\title{
The Intergenerational Legacy of Genocidal Rape: \\ The Realities and Perspectives of Children Born of the Rwandan Genocide
}

\section{The Fallout of the Rwandan Genocide: \\ Understanding Sexual Violence and its Intergenerational Legacy}

In a period of roughly 100 days, more than one million Tutsis and moderate Hutus ${ }^{1}$ were systematically targeted and murdered during the Rwandan genocide (Mamdani, 2001). The genocide was efficiently planned by the Akazu (meaning "little house"), a group of Hutus in power, and the Interahamwe ${ }^{2}$, a faction of the Hutu militia that directed and carried out the mass slaughter of Tutsis across the country. Formal policies of discrimination, intermittent violence, and the systematic preparation for the killing of the Tutsi population have been well documented prior to the bloodshed that characterized the 1994 genocide (Koster, 2008; Nowrojee, 1996).

In the decades leading up to the 1990s, long-standing tensions between the Hutu and Tutsi ethnic groups had engendered years of persecution of the Tutsi minority population under a Hutuled Rwandan government (Umulisa, 2015). In large part, inter-ethnic tensions stemmed from the legacy of European colonization, which had introduced formal policies of ethnic identification for the Hutu, Tutsi, and Twa that mischaracterized pre-colonial Rwandan society and the construction of social identity among these three groups (Hintjens, 1999). The institutionalization of discriminatory policies and practices on the basis of ethnicity encouraged divisive ideology among the Rwandan population that continued after the country gained formal independence from colonial powers in 1962 (Hintjens, 1999). The adoption of such policies by the Rwandan government lay the groundwork for recurrent violence, political oppression, and the mass exodus of the Tutsi population into neighboring countries and abroad over many years (Mamdani, 2001).

\footnotetext{
1 The Hutu, Tutsi, and Twa are the three primary ethnic groups found in Rwanda. The latter two are minority groups. (Mamdani, 2001). Moderate Hutus are those who supported the Tutsi population.

2 Kinyarwanda word meaning "those who attack together".
} 
Exiled Rwandans in Uganda formed the Rwandan Patriotic Front (RPF), a derivative of the movement for national democracy in Rwanda, that demanded repatriation and full citizenship rights for all Rwandans, as well as denounced the monopoly of power held by President Habyarimana since 1973 (Holmes, 2014). The RPF was seen as a legitimate threat to the political status-quo by Hutu extremists, who vehemently opposed the RPF, its demands, and the possibility of peaceful dialogue between President Habyarimana and RPF leaders (Holmes, 2014). 'Hutu power' extremism gained significant momentum in the early 1990s through radio programming on national stations such as Radio Television Mille Colline, which propogated ethno-nationalist ideas that further divided Rwandans along ethnic lines, promoting hate, suspicion and violence (Holmes, 2014; Mamdani, 2001). Indeed, following the assassination of President Habyarimana, in what many describe as a military coup on April $6^{\text {th }} 1994$, the mass killings of Tutsis and moderate Hutus ensued across the country (Holmes, 2014; Hintjens, 1999). Ultimately, it was the invasion of RPF forces and their ability to overthrow the Hutu militia that ended genocidal violence in Rwanda, following more than three months of bloodshed (Hintjens, 1999).

The Rwandan genocide was characterized by brutal acts of sexual violence, with Tutsi and moderate Hutu women and girls being the primary targets of systematic rape, torture, and forced pregnancy (Nowrojee,1996). Importantly, the identity of Tutsi women was employed as an element of propaganda by the Hutu-led government to further alienate and marginalize the Tutsi population, as well as to incite sexual violence (Taylor, 1999; Hintjens, 1999). The first three of the ten "Hutu Commandments" were directed specifically at Tutsi women in order to prohibit "mixed" sexual relations that would threaten the homogeneity of Hutu blood and weaken 'Hutu

\footnotetext{
${ }^{3}$ The Hutu Ten Commandments called for the extermination of the Tutsi population and were published in Kangura, a Kigali newspaper, in 1990.
} 
power' (Taylor, 1999). Extremist propaganda specifically identified the sexuality of Tutsi women as a means through which the Tutsi community sought to infiltrate and control the Hutu population. This propaganda fueled the sexual violence perpetrated against Tutsi women as a means of dehumanizing and subjugating all Tutsi (Nowrojee, 1996).

Acts of sexual violence were perpetrated by members of the Interahamwe, as well as soldiers of Rwanda's Armed Forces (Forces Armées Rwandais), and civilians (Mukangendo, 2007; Mukamana \& Brysiewicz, 2008). It is estimated that 350,000 women and girls were raped during the genocide (Zraly, Rubin, \& Mukamana, 2013). During civilian attacks on villages and fleeing from violence, many women and girls were raped and murdered in the presence of their families (Mukangendo, 2007). Some women and girls were taken captive as "wives" by the Interhamwe and held in captivity for extended periods of time (Mukangendo, 2007; Nowrojee, 1996). Mass rape was strategically employed as a tactic of genocide and ethnic cleansing (Sharlach, 2000). These violations served to not only undermine each individual women's or girls' humanity and dignity, but also functioned to denigrate the broader communities of which these women were a part (Veale, McKay, Worthen, \& Wessells, 2013; Weitsman, 2008). Importantly, these forms of sexual violence inflicted on women persisted long after the "official" end of the genocide, particularly in the context of internally displaced persons (IDP) camps, where displaced populations sought refuge (Mukangendo, 2007; Nowrojee, 1996).

In recent years, the implications of wartime sexual violence - its causes, functions, and impact on victims - have garnered increasing attention at the local, national and international levels (Cohen, Hoover \& Wood, 2013; Isikozlu \& Millard, 2010). However, although sexual violations of rape and forced pregnancy have been codified under international law as acts of genocide and crimes against humanity, consideration for the children born of these crimes has 
remained largely absent from the international human rights and scholarly discourse (Carpenter, 2010). In this sense, the intergenerational fallout from genocidal rape has been largely overlooked and, in particular, the voices and perspectives of those directly implicated - children born of genocidal rape - have been neglected and ignored.

Drawing from a study which included interviews and focus groups with a sample of 60 youth born of the Rwandan genocide, this paper explores the perspectives, lived experiences and needs of children born of genocidal rape. The paper begins with an overview of the issue of children born of genocidal rape in Rwanda. Following an overview of the study's methodology, we highlight the perspectives of youth born of genocidal rape, and in particular the key challenges they identified in their daily lives including issues of identity and belonging, ambivalence in the mother-child relationship, as well as the importance of truth-telling. We conclude with a discussion of the long-term needs of children born of genocidal rape and the opportunities for service provision as identified by the youth themselves. The paper ultimately highlights the intergenerational legacy of sexual violence during armed conflict and its multiple and powerful implications.

\section{Children Born of Genocidal Rape in Rwanda}

Given the dearth of systematic research on the reality of children born of genocidal rape, the number of these children currently living in Rwanda is difficult to establish. The Population Office of Rwanda estimates that 2,000-5,000 children were born in refugee/IDP camps as a direct consequence of rape. However, other sources claim this number to be much higher, upwards of 
10,000 (Mukangendo, 2007; Nowrojee, 1996). The paucity of systematic data on these children speaks to their overall invisibility. According to anecdotal evidence, in the immediate aftermath of the genocide, given their predicament, some pregnant women resorted to desperate acts such as suicide, self-induced/clandestine abortions, abandonment, and in rare cases infanticide (Carpenter, 2010; Mukangendo, 2007). In the rebuilding of their post-genocide lives, female survivors of sexual violence were indeed confronted with multiple structural and social obstacles. Based in dominant cultural traditions, value ascribed to women's sexual "virtue" translated into the severe stigmatization of rape victims. For women who gave birth to children of rape, this stigma was amplified and often passed down to the children who bore the mark of both "illegitimacy" and biological association with the "enemy" (Akello, 2013). This social stigma filtered into all aspects of life, making it difficult for women to remarry or access arable land as a means to support themselves and their children (Mukamana \& Brysiewicz, 2008). Born into the turmoil of major social upheaval, these children - often referred to in Rwanda as "enfants de mauvais souvenirs" (children of bad memories) and "enfants de la haine" (children of hate) became living reminders to mothers and the larger community of the immeasurable suffering they had endured at the hands of their children's fathers (Mukandendo, 2005; Nowrojee, 1996).

Although more than two decades have passed since the genocide and Rwandans have attempted to rebuild and move on with their lives, surprisingly little is known of these children and how they, their mothers, and community members have negotiated relationships and realities of their post-genocide lives. This paper seeks to highlight the realities and perspectives of these children. Before doing so, however, we address the study's methodology. 


\section{Methodology}

This research project, funded by the Social Sciences and Humanities Research Council of Canada, has explored the perspectives and needs of children born of genocidal rape, as well as their mothers and family members. The study is a partnership of researchers at McGill University and Association Tubahumurize, a local Kigali-based non-governmental organization, which supports female victims of violence and marginalization through trauma counselling, income generation training, and a sewing school. As a participatory research project, a group of youth born of genocidal rape were engaged in the study as co-researchers and involved in all aspects of the study. More specifically, three youth born of genocidal rape were provided extensive research training, and were involved in the design of the study, and collected data: they conducted interviews and focus groups with other children born of genocidal rape. The youth researchers were also involved in data analysis, and dissemination of the research findings and are co-authors on this paper.

This study received ethical approval from two research ethics boards: the first from the Rwandan National Ethics Committee, and the second from the Research Ethics Board of McGill University, Canada. The ethical implications of this research were considerable. Participants were being asked questions about their lives that had the potential to both revive traumatic memories and cause significant distress. The potential risks for emotional distress were reviewed with participants as part of the informed consent process prior to their participation. In light of these possibilities, psychosocial support structures were put into place in advance, in the event that a participant should become distressed as a result of interview content and require a referral. 
With participants' permission, Tubahumurize staff followed up post-interview to ensure participants' wellbeing.

In-depth interviews were conducted between June and August 2016 with 60 youth born of genocidal rape ${ }^{4}$. In addition to interviews, youth born of genocidal rape took part in a focus group that was facilitated by a youth researcher. A total of 7 focus groups discussions were held with 8 youth participants in each group ${ }^{5}$. While interview questions aimed to better understand the unique life story of each participant, focus group questions were centered around the collective challenges and needs, sources of support, and the citizenship rights of youth born of genocidal rape.

A snowball sampling technique was used to recruit participants through the professional networks of Association Tubahumurize. Potential participants were identified by and initially contacted by Tubahumurize staff and invited to take part in the study. Participants resided in one of the three following regions of Rwanda: Kigali, Muhanga, Ruhango. These three different regions were selected by the research team in order to explore the realities, similarities and differences of participants living in both rural and urban settings.

Interview and focus groups protocols were developed in collaboration with the entire research team and took into consideration cultural and linguistic nuances. Data was collected through semi-structured open-ended questions, and researchers used probing techniques to elicit detailed

\footnotetext{
${ }^{4}$ Interviews were also conducted with 41 mothers (who were survivors of sexual violence and gave birth to children born of genocidal rape), and 5 family members of the youth participants. These interviews are not included in this analysis.

${ }^{5}$ Four participants were unable to attend focus groups due to competing obligations.
} 
responses from participants. Interviews and focus groups were audio-recorded with participants' permission. Local researchers conducted interviews in Kinyarwanda, while Canadian researchers used English with simultaneous English-Kinyarwanda translation. At the time of interviews and focus groups, participants born of genocidal rape were either 20 or 21 years old, with the exception of one participant, who was $19^{6}$.

Prior to interviews, all participants engaged in an art-making activity that we referred to as the "River of Life." Participants were asked to draw their histories and life courses, using the metaphor of a river, showing the ebbs and flows of their lives. Participants then shared during interviews the meaning of their "River of Life", which allowed participants to explain key events and realities throughout their life course.

Interview and focus group audio files were translated and transcribed from Kinyarwanda to English. A grounded theory approach to data analysis was employed, whereby through careful reading and coding of transcripts the researchers identified key themes that were emerging from the data (Cresswell, 2013). An ongoing discussion of emerging themes by the research team was part of the data analysis process. All names mentioned throughout this paper are pseudonyms in order to protect the identity of participants.

Association Tubahumurize is an non-governmental organization that promotes the empowerment of marginalized women in Rwanda. As study participants were recruited through their

\footnotetext{
${ }^{6}$ The majority of participants were born in 1995 and aged 21 at the time of the interview. However, in a few cases, mothers were abducted and taken to the DRC or in places in Western Rwanda where were held captive and experienced repeated sexual violence over lengthy periods of time. As such, a few of our youth participants were born in 1996. In the case of one youth participant, his mother was a victim of sexual violence when a group of Interahamwe returned to Rwanda in 1996. This participant was thus born in 1997 and aged 19 at the time of the interview.
} 
professional networks, an important sample bias must be noted. In particular, it is likely that women and children from lower socio-economic statuses were over-represented in our sample. Also, given the small sample size, the findings cannot be generalized to the realities of all children born of genocidal rape in Rwanda.

\section{The Realities and Perspectives of Young People Born of Genocidal Rape}

Speaking directly with young Rwandans born of genocidal rape about their lives and experiences offers insight on how these young people survive and cope. For many of the participants, the interviews and focus group discussions were the first time they had openly shared their life story and had been among other youth with a similar background. During interviews, the themes of identity and belonging, ambivalence in the mother-child relationship, and truth-telling emerged as significant thematic areas within the lives of young Rwandans born of genocidal rape. In the following section, we explore the voices and perspectives of these participants in regards to these three themes. The narratives highlight how the lived realities of these young people are shaped by the intergenerational implications of conflict-related sexual violence in profound and complex ways.

\section{"Not Human Beings": Navigating Ethnicity, Identity and Belonging}

The experiences and perspectives shared by young people in this study underscored how their identity as children born of genocidal rape challenged their right to belong within their families and communities. Certainly, in many examples of wartime sexual violence, the stigma attached to the identity of children born of wartime or genocidal rape is entangled within the father's status as an “enemy”, combatant, or ethnic 'other' (Carpenter, 2000; Erjavec \& Volcic, 
2010; Hamel, 2016). Families and societies are often unable to psychologically extricate children born of war/genocide from the violent circumstances surrounding their conception. For this reason, children born of wartime rape are frequently victims of indirect and direct forms of violence, such as abandonment, infanticide, abuse, and discrimination (Carpenter, 2007; Goodhart, 2007; Weitsman, 2008; Denov and Lakor, 2017). Indeed, while the child is a secondary victim of the rapist's assault on the mother, the child is rarely perceived as such by the maternal family (Carpenter, 2000). Subsequently, these children are routinely denied membership to their mother's family and community, even if paternal identity is unknown (Goodhart, 2007; Hamel, 2016). This exclusion demonstrates one of the most profound intergenerational consequences of genocidal rape: the loss of identity and social inclusion experienced by children — an exclusion compounded by their father's perpetrator status, and by the shame surrounding rape that overrules maternal identity (Carpenter, 2000). In other words, in warring societies where policies of mass rape and forced pregnancy occur, the acts of sexual violence resulting in conception often negate a mother's contribution to her child's identity (Delaet, 2008). It may also give rise to the egregious infringements on the human rights of such children throughout their lives (Van Ee \& Kleber, 2013; Weitsman, 2008).

All of the young people in this study described their birth origins as negatively affecting their sense of belonging within their families and communities. Without question, being identified with terms such as "little killer" and "children of hate" led to varying levels of stigmatization and discrimination by family and community members. For many, this meant facing decreased opportunities for education and economic support, lack of care and affection, as well as in many cases verbal, physical, or sexual harassment and abuse. Young people frequently 
acknowledged how, from an early age, they were cognisant of their differential treatment and rejection within the home:

Yes, when I was nine years old, I recall that they [maternal family] used to treat me in a very bad way. I was working very hard at home. I did my primary in a poor quality school, yet my cousins were sent to good schools by my aunts. It was even hard to do my homework because I was all the time busy doing [chores] while others were busy only with their studies (Madeline).

Here [explaining her "river of life"] is when I used to be beaten by my aunt...They used to ask me to do all the [chores] at home and to stay at home. I could not go to play with other children. In that case I was beaten. Then at twenty years [of age], I gave birth to my child, and I thought my life is going to be worse. (Jannine)

Most young people resided with their maternal families and lived in a household with extended relatives, such as aunts, uncles, or grandparents. Others had been raised alone by their mother or in the context of a 'new' family, in cases where mothers had remarried. This meant that most young people had to overcome the challenges of "fitting in" among existing family structures, which further complicated young people's relationships, especially with half-siblings. One participant recounted his experiences of exclusion:

I have two half siblings. They share the same dad and mum and I am in the middle of them. It is hard to understand right? My mother was married and had a kid before the genocide and during the genocide she was raped and had me. After she returned with her husband, she had another child. So in their family, I feel like I don't belong there (Georges).

However, participants' experiences of rejection and exclusion were not limited to maternal families. While establishing paternal identity was nearly impossible for many participants (their mothers had been gang-raped or subjected to multiple rapes), other participants had met or known their father or paternal family. In some cases, where paternal identity and family were known, participants described an overarching rejection from both sides of their families that made them feel like outsiders. As this participant explained: “It wouldn't only be [rejection] from your 
mother's family, but your father's family too. You feel like you belong nowhere" (Jean). Indeed, some young people spoke about how their paternal relatives, including their fathers, rejected them because they were perceived as belonging to their maternal family and inter-ethnic tensions and ideas remained post-genocide:

I don't have a relationship with my dad. I can't go to my father's side [of the family]. Even when we meet, he says to me: ">ook at you, you look like your mother, a snake [a Tutsi].” He is always insulting me. But it doesn't affect me anymore (Mohammed).

Experiences of differential treatment, stigmatization, and exclusion were often the sources of shame, confusion, and anguish for many participants. Furthermore, some participants reported encountering verbal harassment, such as insults and name-calling by family, neighbours, peers, teachers, or other community members that made them self-conscious, often leading them to question their origins, their sense of belonging and importantly, their identity:

I was confused. They [neighbors] were saying that my mother has children who are Tutsis and others who are Hutus and I didn't know what that was. And it was hard to accept myself. I had a complex. I started feeling ashamed (Erica).

Another problem that I see is in your family you become something else. You are not a human being. They are always calling you bad names that makes you not to accept yourself. Some of them say to you that: "Your dad killed our families".... There are many things that are in people's brain that make them see us as people that are not human beings. And when you have grown up not treated like a human being it affects you a lot. It causes you to lose your self-confidence. You feel like nothing, and life has no sense. While others are building their futures, you are just there asking yourself "why and why"? (Jean)

In addition to instances of abuse and maltreatment within the home, a number of participants reported fearing for their physical safety from community members because of their identity as children born of genocidal rape. One participant recalled how her family received threats of physical violence after her mother provided testimony in the Gacaca that had identified and testified against her perpetrators of sexual violence. As living "proof" of rape - a genocide 
crime - this participant described how her mother's life and her own life had been at risk.

Eventually, the severity of the threats compelled her family to leave their community of origin:

We had many risks of being attacked. In the night, people were coming to our house and threatening to kill us. They wanted to kill us because my mother testified at the Gacaca. The people she testified against went to prison. So...we were at risk of being killed [by the perpetrators family]. We moved and came to Kigali (Erica).

Without question, many young people in this study faced severe social stigma and marginalization because of their identity as children born of genocidal rape. Indeed, the identities of such children were central to their exclusion from family and community members.

Experiences of stigmatization shaped the lives of these young people and engendered profound challenges pertaining to their self-concept and self-esteem.

\section{Ambivalence in the Mother-Child Relationship}

One the most significant relationships reported by participants was the relationship with their mothers, even in cases of long-term separation, abandonment, maltreatment, or death. When characterizing the mother-child bond, most young people noted or described a variety of emotions and gave a detailed account of their experiences throughout their lives. Only a few participants resolutely stated that they never had any "problem" with their mothers. All other participants identified significant challenges within the mother-child relationship, at times describing mutual love and affection, while at other times describing maltreatment, profound tension, and sometimes abuse. Most young people understood the complexities and challenges in the mother-child relationship as originating from the circumstance surrounding their conception.

One male participant described his mother's severe treatment and attitude towards him, as well as his rejection of her as a maternal figure: 
When I was young she used to beat me so much that even our neighbors were wondering if she was really my mother. Another example is that she can't give me a single coin when I am in urgent need.... My mum has never shown that she loves me since I've known her. I consider [my aunt] as my mother...It [mother-child relationship] is not good. She goes to work early in the morning, I don't say good morning. And when she is back in the evening it is like that. We may pass three weeks without talking to each other. And she used to use harsh words against me. I don't like her (Jeremie).

For other young people, the mother-child relationship was ambiguous and challenging to navigate. The varying treatment of young people throughout their lives by their mothers and the maternal side of the family made it difficult for participants to clearly ascertain if their mothers cared for them. Participants' described the ambivalence, uncertainty, and vacillation within the mother-child relationship, as well as the harsh words that came from their mothers:

She [mother] would say that I caused all this, I screwed everything up and sometimes she [would say that she] did not want to be with me. Saying like.... She will never love me again...But later I could hear her apologizing again... And then she [mother] would feel guilty... (Madeline).

She [mother] gets mad easily, like if you make a mistake, it reminds her of all the things she has been through and she is very mad at you. When it happens, she says many bad things to me that break my heart. But I have to know how to manage it (Erica).

Another male participant reflected on his relationship with his mother over the course of his life, acknowledging an overall lack of "maternal care":

When I was seven years old, I noticed the way she [mother] was treating me differently from my brothers... The relationship is now almost good, though me and her know that she used to be traumatized by the fact that I was born from an unwanted pregnancy. Due to that trauma she was not open to me. Even now we have never talked about how she was treating me in such a manner.... What I don't like the most is that she did not provide maternal care as other children normally get from their mothers (Georges).

This participant described how the lack of maternal care he received from his mother was directly related to his birth origins, as an 'unwanted pregnancy.' The above quote highlights the intergenerational impact of rape on the mother-child bond and an awareness shared by many 
participants of how the violent circumstances surrounding their conception continued to influence this relationship. Similar accounts were reported by many other participants, often depicting a tenuous, complex mother-child relationship that was dependent on mothers' moods and feelings from moment to moment. However, in spite of the reported ambivalent treatment by their mothers and challenges present in their relationship, many young people reported their deep and unequivocal love for their mothers, as well as having compassion for their mothers' postgenocide hardships. Indeed, young people were aware of how their own identities as "children of killers" had often resulted in the rejection and stigmatization of their mothers, and this had a profound influence on participants' views and perceptions of the sacrifices their mothers had made for them:

She has sacrificed her life for me, she has been a good mother for me. When everyone abandoned her [because of] me, she didn't leave me, she continued to love me unconditionally (Divine).

Moreover, it is clear that young people held a great deal of concern for their mothers' well-being and often expressed feeling a strong sense of responsibility for improving their mother's lives. As one young man stated:

My mom is a strong born. She loves me, I love her.... When I remember all what she did for me. I feel I love her too much, because she did whatever she could do when she had nothing. All this encourages me to focus on my studies and think about my future instead of sticking to the past.... So, I thought I have to work hard to become a man and change her life, make her happy (Sebastian).

The experiences and stories shared by young people illustrate how the mother-child relationship played a pivotal role in shaping their lives and held a unique importance for them. While it is clear that many described profound affection and caring for their mothers, young people also described feeling responsible for their mother's difficulties, as well as often being a scapegoat for blame and anger. A lack of maternal care and affection, ambivalent treatment, and 
at times physical abuse, made forming a secure and lasting bond challenging for many

participants, who tried to navigate the complexities present within the mother-child relationship.

\section{The Need to Know: The Importance of Truth-Telling}

For all participants, knowing the 'truth' about their origins was described as extremely important and a critical aspect of their lives. Many young people had learned the 'truth' from their mothers, which held particular significance for them. The question of paternal identity was reported as a major concern, and many participants described having rigorously questioned their mothers as young children and adolescents for details regarding their father's identity. In addition, young people frequently mentioned that they had first heard about their origins through the insults, comments, or stories told by family and community members. For those participants who had not discussed their birth origins with their mothers, the desire to have such a conversation remained a primary preoccupation and many lingering questions remained. One young woman described how she learned about her history:

My mother didn't tell us. I've heard it from neighbours and I met some people who knew my mother before or during the genocide and they are the ones who told me...I have accepted it, but it makes me sad every time.... I can't spend a day without thinking about it (Erica).

Many young people seeking the 'truth' from their mothers were hoping to have them contradict or verify the information that had already been shared with them. However, knowing the 'truth' about their origins meant having their mother explain and acknowledge her traumatic past. Certainly, learning the 'truth' about their origins was deeply painful for participants, even if they had already suspected that they were conceived of genocidal rape. Furthermore, 'truth- 
telling' often revealed other painful secrets and experiences shared between mothers and their children, as these participants described:

That's when she made me sit and told me.... I produced you in the way I hadn't planned, as myself I did not want it. There was even time when I felt like throwing you away [crying], and I was looking for a place where to leave you.... She then asked me to forgive her, [deep breath] forgiveness because of what she was going to do [to me] [deep sigh] (Madeline).

Before I knew the way in which I was born, I did not have any problems. When I learnt about my story, I felt a lot of changes inside, and I realized the reason why my mother was always angry with me, using harsh words against me for any small mistake, especially during [the genocide] memorial period. Now I understand her reactions. She suffered a lot during genocide against Tutsis. I have accepted it since I know the truth (Jola).

As demonstrated above, young people learning about their birth origins and mother's genocide experiences often meant having a frank conversation about their mother's attitude and treatment of them. The sharing of such personal stories deeply affected the mother-child relationship, sometimes in a positive way: "Knowing the truth increased our friendship and love. I don't have any problem with her" (Yvette). Other participants described having mixed feelings: "When I learned about my story [from others], I felt I didn't love her [mother]. But later when I knew the truth [from mother] I started loving her, though I feel I am not open to her" (Jola).

After learning the 'truth,' participants described a host of emotional challenges and reactions. However, many young people were able to make sense and cope with their situation over time. Indeed, some participants recounted how knowing about their origins eventually helped them to better "accept" themselves in spite of experiences of rejection and stigmatization. In some cases, knowing their personal history was a source of strength and a reason to look towards the future: 
Right after knowing that I am the only one who has a different father from my siblings, it made me feel unhappy.... Later on I understood it and I started to build on it.... and this has helped me to know who I am, and those people who used to insult me have come to know who I am... I have accepted everything that has happened to me. Through my story I have started to search for ways that I can use (it) to shape my future (Katherine).

When I became a teenager, my mother told me she wanted to have a conversation with me. Then she told me the way in which I was born, how my father raped her and how he was among the killers during genocide. I was so sad and I was affected a lot. But as time went on and because I like to pray, I was able to accept that situation. One day I read the Bible and God was telling me that I am a chosen generation. This encouraged me a lot. [At that time] I was starting to go with groups that were taking drugs. I stopped it. (Aaron)

Knowing about their personal history became a source of strength to many young people, despite the daily challenges they faced as a result of their birth origins. While not all young people in this study reported they had 'accepted' their 'truth,' having information about the experiences leading up to conception was important in order for them to make sense of their present day relationships and experiences. Moreover, 'truth-telling' from mothers was a particularly important moment for many young people, and influenced the mother-child relationship. And while knowing the 'truth' for many participants was crucial for forming their own sense of self, it may have also given rise to further questions about their own origins that mothers were often unable to answer.

\section{The Intergenerational Legacy of Genocidal Rape:}

\section{Implications for Policy \& Service Provision}

Sexual violence during armed conflict is one of the most frequently occurring wartime human rights abuses. And yet, despite the growing attention to the phenomenon of sexual violence during war and genocide, its intergenerational effects remain poorly understood. This study, 
drawing directly upon the voices of children born of genocidal rape, has demonstrated the profound ways in which sexual violence during armed conflict affects not only the individual woman or girl who has been raped, but those children born as a result of the rape. In the more than two decades since the genocide, Rwandan women and their children born of rape, who are now young adults, are still living with the lasting consequences of sexual violence. Narratives from these youth have underscored the stigma and rejection they experience from their own mothers, from extended family members and from broader members of the community. These experiences of stigma have a significant impact upon their sense of community and family belonging and their sense of identity. As interviews and focus groups revealed, children born of genocidal rape in Rwanda are exposed to multiple traumatic events based upon their origins, including psychological abuse, violence, persecution, forced displacement, and multiple forms of loss, which can seriously harm a child's development and wellbeing (Saul, 2014). Moreover, interviews with participants uncovered ambivalence within the mother/child relationship that influenced, both positively and negatively, the ways in which participants experienced life within and outside of their families. Finally, the desire to know the "truth" about their origins and identity was of utmost importance to participants. While painful and often debilitating, knowing the truth enabled participants to understand themselves and their mothers, sometimes providing a source of strength and way to move forward. Nonetheless the voices of children born of conflictrelated sexual violence show that they face a distinct set of needs across the lifespan. And yet, while the Rwandan Government's has established a fund to support genocide survivors through the "Fund for Neediest Survivors of Genocide in Rwanda" (FARG), children born of genocidal rape remain ineligible to receive financial compensation or support from FARG due to the fact that they were born after 1994 (Hamel, 2016). 
In addition to better understanding young people's perspectives and lived experiences, a key aim of this project was to gain knowledge concerning the views of children born of genocidal rape with regard to service provision and how to address their perceived needs and challenges. Children and youth are rarely consulted in policy-making processes despite that in their role as service users, they have significant input to contribute to the evaluation and formulation of policies (Denov, 2015). Children born of genocidal rape should therefore not be viewed as mere policy 'beneficiaries', but as having "valid insights into their well-being, valid solutions to their problems, and a valid role in implementing those solutions" (Boyden \& Mann, 2005:19) and should ultimately be involved in policy-making and implementation. As Hilker and Fraser (2009) argue: "it is critical that youth are involved in programme design, implementation and evaluation. Young people often have a clear understanding of their own situation and needs and how these relate to the needs of others" (p. 43). To this end, in this concluding section, we draw directly upon the voices of participants and in particular, their views on the service provision and policy needs of children born of genocidal rape that were garnered during focus group discussions, which were led, facilitated and analyzed by the youth researchers. In the context of these focus groups, the youth provided specific direction and areas for future service provision and policy. These areas included youth-led initiatives for peer support and community building, the creation of protective laws and policies, and sensitization programs for reconciliation and unity. These themes are addressed in greater detail below.

\section{Promoting Belonging: Youth-led Initiatives for Peer Support and Community Building} The young people in the study reported that participating in the focus group discussions had a profound impact on their lives. Knowing that others had similar experiences as children born of 
genocidal rape was of particular significance and generated discussion on future activities that could connect young people to one another. As these participants explained:

I think we are all very happy to have had this meeting. Now we have become brothers and sisters. Let us work hand in hand to help each other (Jean)

For me, having met people with the same problems is a solution to my life (Yvette)

For this reason, in order to address the realities of stigma, isolation, and the need for belonging, a number of youth-led initiatives were suggested in order to continue group discussions and to provide peer-to-peer support. One such suggestion was the creation of an association for children born of genocidal rape, similar in structure to other associations for genocide survivors, in which group members would meet on a regular basis to "give advice" and "find solutions" to each other's problems. Forming a peer-based support network was thought to be able to engender a sense of belonging and community among participants, who felt isolated in their experiences of social rejection and stigmatization. Moreover, focus group discussions fostered an awareness of the different sets of challenges facing young people. Continuing to meet as a group was described by some young people as a potential antidote for those in the cohort who may have turned toward "bad behavior" such as taking drugs or alcohol, fighting, or engaging in sex work.

Moreover, such a support network could give rise to action. Not only would group meetings be a forum for young people to socialize and provide each other with emotional support, but it would also be a means strengthen their collective voice as a group. Indeed, many young people saw coming together as an opportunity for community building and to organize themselves to raise awareness among family and community members, as well as in broader social arenas on the pressing issues they were facing as a group of marginalized youth. As a result of these suggestions, the research team has continued to support the youth in their desire to 
meet as a collective. Since the end of the data collection, the research team has acquired temporary funds to enable the youth to meet regularly as a group, and to provide one another with peer-support.

\section{Promoting Advocacy and Social Change: The Creation of Protective Laws and Policies}

Participants identified the need for advocacy in order to shed light on the ongoing hardships particular to young people born of genocidal rape, to break the stigma attached to their identities as "little killers," and to create positive social change. Individually and throughout focus group discussions, participants noted the lack of formal policies that recognize young people born of genocidal rape. Many young people described how they believed their current life situation was a direct result of the genocide, a circumstance that made their lives different from other young people who were not born from genocidal rape. In other words, while young people recognized that they were not "survivors" of the genocide, many considered themselves as "victims" of the genocide crimes perpetrated against their mothers and families. For this reason, participants overwhelmingly called for an official acknowledgement by the Rwandan government as a group in Rwandan society whose origins are inextricably linked to the genocide.

Given the far-reaching impact of the genocide on their lives, an official acknowledgement was important for all of the young people involved in the research project but even more so for those who described their experiences as a violation of their rights, such as the right to belong to a family and community, to receive an education, and to have equal opportunities for socioeconomic advancement. As a first step towards rectifying such violations, young people suggested that existing legal structures and governmental bodies, such as the FARG, adopt inclusive policies that make children born of genocidal rape eligible for similar benefits that are afforded to genocide survivors, as well as the creation of laws to prevent stigma and abuse. 
Moreover, in light of the decreased educational opportunities facing youth, young people reported that funding or subsidies for university studies or vocational training as a potential program that would be extremely valuable for their futures.

\section{Community Sensitization and Social Justice: Programs for Reconciliation and Unity}

Throughout the study, to address the stigma and marginalization they faced, youth identified a need for community sensitization programs or projects that would allow them to share collective experiences of marginalization and move towards greater unity within their respective families and communities. In addition, given the status of participants as having links to both 'perpetrators' and 'survivors' of the genocide, participants saw themselves as an emblem of social reconciliation between these two groups. One young person even suggested that children born of genocidal rape should be taken as a symbol of reconciliation for the future of Rwanda. For this reason, programs aiming to raise community awareness of the unique situation of children born of genocidal rape emerged as a priority from the focus group discussions and led to many young people to conceptualize potential programs that would further advance reconciliation and unity.

One example of a potential program the young people suggested was a Gacaca-like process in which young people would be given the opportunity to address community members in a public space. Such a program would provide an arena for young people to directly share their experiences and to address ongoing community stigmatization and marginalization. By mirroring the Gacaca - an existing and accepted form of community reconciliation - such a program could give rise to concrete changes in the attitude towards and treatment of children born of genocidal rape by families and communities members. 
Another proposed avenue for community sensitization, reconciliation, and unity was through the arts. Young people considered creating a fictional play, which would depict the challenges facing young people born of genocidal rape. Creating and performing such a play would empower young people to actively share their experiences, while simultaneously raising community awareness. Furthermore, a play would be a significant contribution to the dominant discourse surrounding the effects of the genocidal on Rwandan society, which has largely ignored the life stories and existence of such children. At the time of writing, the youth were writing the play's script and were planning to perform the play to an audience in Kigali.

As demonstrated through the voices and perspectives of the young people in this study, the stigmatization of children born of rape has led to enormous real-life obstacles for their social integration and advancement in post-genocide Rwanda. The shared life experiences of participants illustrate the multiple, profound, and intergenerational repercussions of sexual violence during armed conflict and genocide on both mothers and children. However, in spite of differential treatment, rejection, stigmatization, and abuse young people demonstrated great resilience and ingenuity in trying solve their own problems and cope with their situation. In the face of much adversity, young people continued to strive to better their own situation, as well as create a meaningful place for themselves within their families and communities. The insightful and thoughtful service provision and policy suggestions of participants further underscore that young people should be consulted and acknowledged as experts. Their valuable contributions have the potential to dramatically raise the quality of life of this unique population of youth, who sadly remain largely ignored in present day international social and legal frameworks. Without question, it is crucial for children born of conflict-related sexual violence to gain recognition and 
a more prominent place in post-war and genocide policies and services. A concerted effort is needed to acknowledge and address the unique needs of children born of war and genocide long after the conflict may have ended.

\section{References}

Akello, G. (2013). Experiences of forced mothers in northern Uganda. Intervention, 11, 2, 149156.

Boyden, J., and Mann, G. (2005). Children's risk, resilience and coping in extreme situations. In Ungar, M. (Ed). Handbook for working with children and youth: Pathways to resilience across cultures and contexts (pp. 3-27). Thousand Oaks, CA: Sage Publications.

Carpenter, R. C. (2000). Forced maternity, children's rights and the genocide convention. Journal of Genocide Research, 2(2), 213-244.

Carpenter, R. C. (2007). Born of war: Protecting children of sexual violence survivors in conflict zones. Bloomfield, CT: Kumarian Press.

Carpenter, R.C. (2010) Forgetting children born of war: Setting the human rights agenda in Bosnia and beyond. New York, NY: Columbia University Press.

Cohen, D., Hoover, G., E., A., and Wood, E. (2013). Wartime sexual violence: misconceptions, implicationsm and ways forward. Washington, United States Institute of Peace.

Cresswell, J. (2013). Qualitative inquiry and research design: Choosing among five traditions. Thousands Oaks, CA: Sage Publications.

DeLaet, D. L. (2008). Gender, sexual violence and justice in war-torn societies. Global Change, Peace \& Security, 20(3), 323-338. doi:10.1080/14781150802394055 
Denov, M. (2015). Children born of wartime rape: The intergenerational realities of sexual violence and abuse. Ethics, Medicine and Public Health, 11, 61-68.

Denov, M. and Lakor A.A. (2017a) Post-War Stigma, Violence, \& "Kony Children":

The Responsibility to Protect Children Born in Lord's Resistance Army Captivity in Northern Uganda. Unpublished Manuscript.

Denov, M. and Lakor, A.A. (2017) When War is Better Than Peace: The Post-Conflict Realities of Children Born of Wartime Rape in Northern Uganda. Child Abuse and Neglect, 65: 255-265.

Erjavec, K., \& Volcic, Z. (2010). Living with the sins of their fathers: An analysis of SelfRepresentation of Adolescents Born of War Rape. Journal of Adolescent Research, 25(3), 359.

Goodhart, M. (2007). Sins of the fathers: War rape, wrongful procreation, and children's human Rights. Journal of Human Rights, 6(3), 307-324.

Hamel, M. E. (2016). Ethnic belonging of the children born out of rape in post conflict BosniaHerzegovina and Rwanda. Nations and Nationalism.

Hilker, L. M., and Fraser E. M. (2009). Youth Exclusion, Violence, Conflict and Fragile States. Report prepared for DFID by Social Development Direct, London.

Hintjens, H. M. (1999). Explaining the 1994 Genocide in Rwanda. The Journal of Modern African Studies, 37, 2, 241-286.

Holmes, G. (2014). Women and war in Rwanda: Gender, media and the representation of genocide. New York: NY. Palgrave Macmillan.

Isikozlu, E., and Millard, A., S. (2010). Towards a typology of wartime rape. Bonn: Bonn International Center for Conversion. 
Kantengwa, O. (2014). How motherhood triumphs over trauma among mothers with children from genocidal rape in Rwanda. Journal of Social and Political Psychology, 2(1), 417434. Doi: 10.5964/jspp.v2i1.334.

Mamdani, M. (2001). When victims become killers: Colonialism, nativism, and the genocide in Rwanda. Princeton, N.J: Princeton University Press.

Mukamana, D. \& Brysiewicz, P. (2008). The lived experience of genocide rape survivors of Rwanda. Journal of Nursing Scholarship, 40, 379-384.

Mukangendo, M.C. (2007). Caring for children born of rape in Rwanda. In R.C. Carpenter (ed.), Born of war: Protecting children of sexual violence survivors in conflict zones. Bloomfield, CT: Kumarian

Nowrojee, B. (September 1996). Shattered lives: Sexual violence during the Rwanda genocide and its aftermath. Human Rights Watch Africa, Human Rights Watch Women's Rights Project.

Saul, J. (2014). Introduction: Collective trauma, resilience, and recovery. (pp. 1 - 16). In Collective Trauma, Collective Healing: Promoting community Resilience in the Aftermath of Disaster. New York, NY: Routledge.

Sharlach, L. (2000). Rape as genocide: Bangladesh, the former Yugoslavia, and Rwanda. New Political Science, 22(1), 89-102.

Taylor, C. C. (May 01, 1999). A Gendered Genocide: Tutsi Women and Hutu Extremists in the 1994 Rwanda Genocide. Polar: Political Legal Anthropology Review, 22(1), 42-54.

Umulisa, C. (2015). We are Also Mothers: Rwandan Women with Children Born of Genocide. In Sgoutas, A., \& Takseva, T. (Eds). Mothers Under Fire: Mothering in Conflict Areas (pp. 137-154). Bradford, ON: Demeter Press. 
Van Ee, E., \& Kleber, R. J. (2013). Growing Up Under a Shadow: Key Issues in Research on and Treatment of Children Born of Rape. Child Abuse Rev. Child Abuse Review, 22(6), 386397.

Veale, A., McKay, S., Worthen, M., \& Wessells, M. G. (September 01, 2013). Participation as principle and tool in social reintegration: Young mothers formerly associated with armed groups in Sierra Leone, Liberia, and Northern Uganda. Journal of Aggression, Maltreatment and Trauma, 22, 8, 829-848.

Weitsman, P.A. (2008). The politics of identity and sexual violence: A review of Bosnia and Rwanda. Human Rights Quarterly, 30(3), 561-578.

Wielenga, C. (2014). 'Lived' identities in Rwanda - beyond ethnicity? Africa Insight, 44(1), 122136.

Zraly, M., Rubin, S. E., \& Mukamana, D. (2013). Motherhood and Resilience among Rwandan Genocide-Rape Survivors. Ethos, 41(4), 411-439. 